\title{
CHANGES IN SOLUBLE PROTEIN PROFILE IN COTTON LEAVES INDICATE RUBISCO DAMAGE AFTER TREATMENT WITH SUMI-ALPHA INSECTICIDE
}

\author{
AKMAL M. ASROROV ${ }^{1 *}$, ILDIKÓ MATUŠÍKOVÁ ${ }^{2}$, JAMOLITDIN F. ZIYAVITDINOV ${ }^{1}$, \\ ZUZANA GREGOROVÁ ${ }^{2}$, VIERA MAJERČÍKOVÁ ${ }^{3}$, AZIMJON A. MAMADRAKHIMOV ${ }^{1}$ \\ ${ }^{1}$ Institute of Bioorganic Chemistry, Academy of Sciences of Uzbekistan, Tashkent, Uzbekistan \\ ${ }^{2}$ University of SS. Cyril and Methodius in Trnava, Slovak Republic \\ ${ }^{3}$ Institute of Plant Genetics and Biotechnology, Nitra, Slovak Republic
}

ASROROV, A.M. - MATUŠÍKOVÁ, I. - ZIYAVITDINOV, J.F. - GREGOROVÁ, Z. - MAJERČíKOVÁ, V. MAMADRAKHIMOV, A.A.: Changes in soluble protein profile in cotton leaves indicate RuBisCo damage after treatment with Sumi-Alpha insecticide. Agriculture (Pol'nohospodárstvo), vol. 66, 2020, no. 1, pp. $40-44$.

\begin{abstract}
The cotton plant suffers from many pests and due to its economic importance, the use of efficient but ecologically friendly pesticides is highly desirable. The insecticide Sumi-Alpha with active compound Esfenvalerate is widely used for cotton treatment in Uzbekistan. This insecticide is considered as moderately hazardous for different organisms of ecosystems, while more collected data and relevant research is a necessity for judgement of their safety and/or potential risk. Therefore, a comparative analysis of cotton leaves was performed to study the protein profile changes upon treatment with this insecticide. Our data showed elevated accumulation of fructose bisphosphate aldolase and degradation of RuBisCo in the treated tissue. Besides, a protein belonging to P-loop containing nucleoside triphosphate hydrolases superfamily exerted lower accumulation. Our results indicate that the applied pyrethroid pesticide possibly can affect photosynthesis performance and cause accumulation of simple saccharides which in turn might contribute to enhanced colonisation of sucking insects. Further molecular research on Sumi-Alpha effects on cotton is necessary for its safer use in agricultural practice.
\end{abstract}

Key words: cotton plant, Sumi-Alpha, RuBisCo, fructose bisphosphate aldolase

Up to $26-29 \%$ of the cotton crop is estimated to be lost by pests (Oerke 2004) and to save the crop, plants are necessarily treated with agrochemicals against insect-pests. Thus, a significant part of the production is saved. In this manner carbamates, organophosphates, pyrethroids are widely used (Zahid \& Hamed 2003; Carneiro et al. 2014). Comparing to other classes, pyrethroid insecticides are often preferred because of efficiency in low doses. However, their usage in some regions, are linked with the resurgence of sucking pests: aphid and mites, in hot seasons. In Uzbekistan, pyrethroids were found to stimulate the development of sucking pests. The pyrethroid efficiency ranged between $15-25 \%$ was observed for two weeks in treated plots, whereas aphids' number naturally lowered 2-3 times in untreated fields (Asrorov et al. 2013).

Asrorov Akmal M. ("Corresponding author), Ziyavitdinov Jamolitdin F., Mamadrakhimov Azimjon A., Laboratory of Proteins and Peptides Chemistry, A.S. Sadykov Institute of Bioorganic Chemistry, Academy of Sciences of Uzbekistan, M. Ulughbek 83, Tashkent, Uzbekistan. E-mail: akmal84a@gmail.com

Matušíková Ildikó, Gregorová Zuzana, Department of Ecochemistry and Radioecology, Faculty of Natural Sciences, University of SS. Cyril and Methodius in Trnava, Nám. J. Herdu 2, 91701 Trnava, Slovak Republic

Majerčíková Viera, Department of Reproduction and Developmental Biology, Institute of Plant Genetics and Biotechnology, Akademická 2, P.O. Box 39A, 95007 Nitra, Slovak Republic 
Aphids demonstrated high resistance to pyrethroid insecticides: cypermethrin, $\alpha$-cypermethrin, zeta-cypermethrin, cyfluthrin, fenpropathrin, bifenthrin, and $\lambda$-cyhalothrin which are efficiently used against cotton bollworm (Amad et al. 2003). Preventing sucking pests' resurgence in cotton plants after treatment with insecticide preparation makes it necessary to study their effects on the level of photosynthesis and/or sugars in plants.

The effects of the same agrochemicals on photosynthesis-related processes differ in various plants. Esfenvalerate, the active ingredient of Sumi-Alpha, did not cause changes in chlorophyll a and b content in radish (El-Daly 2006). But in cotton, treatment with fenvalerate, deltamethrin, and cypermethrin (all with esfenvalerate as the active ingredient) led to higher accumulation of sugars (Ravindhran \& Xavier 1997). Moreover, a similar product Sumi-Alpha has been shown to cause accumulation of higher quantities of essential amino acids, which also supports aphid resurgence (Asrorov et al. 2015).

In this work, chlorophyll fluorescence yield of cotton plant was studied after treatment with Sumi-Alpha preparation in comparison with control, qualitative and quantitative changes of soluble protein profiles were established by two-dimensional electrophoresis (2DE) and further mass spectrometric analysis with an intension to identify possible changes around photosynthesis-related enzymes upon treatment.

Cotton plants were treated with Sumi-Alpha once, and on the $10^{\text {th }}$ day of the treatment, the plant leaves were taken for analysis. No visible morpho-physiological differences comparing to mock-treated controls were observed. To assess their physiological status, we also measured the chlorophyll fluorescence that is considered a good indicator of impaired photosynthetic electron transport chain under stress on the same day of the treatment (Juneau et al. 2007). The Fv/Fm ratio of insecticide-treated plants significantly increased (Figure 1).

Previous works with other pyrethroid compounds (permethrin, cypermethrin, deltamethrin and fenvalerate at maximal allowed doses) report no appreciable impact on fluorescence parameters (Rózsavölgyi \& Horváth 2008). Significant influences of phorate, phoxim, and cypermetrin have been shown in Chinese cabbage after 3 days of treatment (Gao et al. 2010). A minor, yet significantly positive effect of Sumi-Alpha on photosynthesis quantum yield of cotton plants is in agreement with the absence of any sign of agrochemical toxicity

The changes in photosynthetic parameters are likely reflected also at other levels such as gene expression or protein accumulation. Therefore, the cotton leaf proteome was analyzed to reveal a possible impact of the insecticide. In the protein profiles, obtained, a total of 11 distinguishable protein spots were identified. Changes in the protein expression levels were studied by two-dimensional electrophoresis following isoelectric focusing, carried at $20^{\circ} \mathrm{C}$ for 18 hours. SDS PAAG gel was used for their separation, based on molecular mass. Further, differently expressed proteins were extracted from the gel.

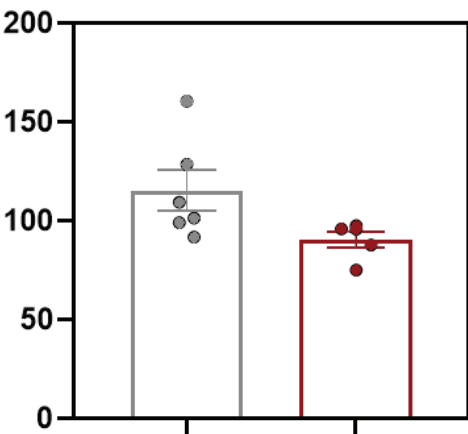

Fo

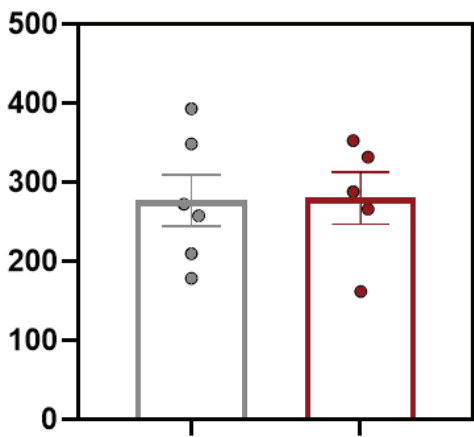

$\mathrm{Fp}$

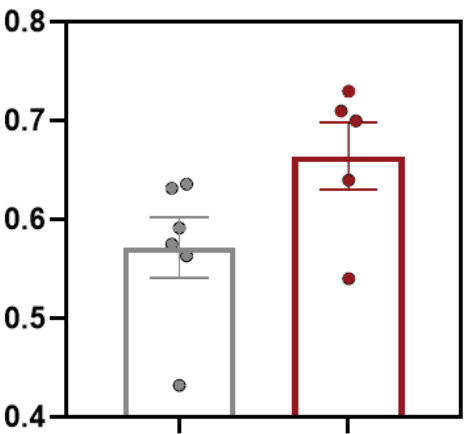

Fv/Fm

Figure 1. Effects of Sumi-Alpha treatment on photosynthetic parameters

*Y axis mean values stand for Fo, Fp and relative quantum yield Fv/Fm values in control and insecticide-treated plants on the $10^{\text {th }}$ day of the treatment. The dark grey column shows the control leaves, and the treated samples are indicated in dark pink colour. Error bars indicate SEM value. 
Partial sequences of proteins were established by subjecting to mass spectrometry analysis performed in CHIP-Q-TOF LC-MS Agilent Technologies 6520B Series mass spectrometer. Obtained results were proven by checking in NCBI (www.ncbi.nlm. nih.gov), the Phytozome v.12 (http://phytozome.jgi. doe.gov) and UniProt (www.uniprot.org) databases. Among distinguishable spots, only 4 (2, 3, 4a and $4 \mathrm{~b}$ spots) showed differential accumulation rates as a consequence of insecticide treatment and/or resulted in the formation of new spots (Figure 2).

The highly abundant 1 spot (Figure 2) revealed full similarity to RuBisCo (EC 4.1.1.39) large subunit $(R b s L)$ (Table 1). The accumulation of RbsL partial sequence (RbsLPS), found in the chloroplast (Roy et al. 2010), was suppressed in treated plant leaves (spot 2 in Figure 2). In contrast, the expression of fructose bisphosphate aldolase (EC 4.1.2.13) was significantly higher in treated plant leaves (3 spots in Figure 2). The two additional spots with differential accumulation after Sumi-Alpha treatment include proteins/peptides corresponding to nucleoside triphosphate hydrolase with a sequence consisted of ten amino acids.

Though the impact of Sumi-Alpha on cotton regarding increased attractiveness to sucking pests is well known, the physiological or molecular studies on possible impacts on plants are still missing. The present study revealed a significant impact of the insecticide Sumi-Alpha on the RuBisCo large subunit and/or its partial sequence, playing a crucial role in carbon fixation. Plants encode one highly conserved so-called green-type form I enzyme, consisting of eight $\sim 52 \mathrm{kDa}$ large subunits and eight $\sim 15 \mathrm{kDa}$ small subunits $\left(\mathrm{L}_{8} \mathrm{~S}_{8}\right.$ ) (Andersson \& Backlund 2008). The identified $R b s L$ fragments (spot 1 in Figure 2) correspond to the $53.3 \mathrm{kDa}$ isoform consisting of 480 amino acid residues (NCBI reference YP_538943.1) and covers 32\% of the whole protein sequence (Table 1).

The smaller-size spot 2d (Figure 2) revealing high sequence similarity to RuBisCo subunits (Table 1) was considered as degradation products of $R b s L$ and/or RbsLPS. Degradation of RuBisCo large and small subunits was reported in wheat plants as a result of modelling pathways (Tétard-Jones et al. 2014). Elevated chlorophyll fluorescence in treated cotton leaves does not correspond with the degradation of RuBisCo which possibly leads to decreased $\mathrm{CO}_{2}$ fixation rate. On the other hand, the high colour intensity of RbsL (spot 1) in 2DE does not allow its quantification that could fix its affection in the protein level.

In contrast to $\mathrm{RuBisCo}$, the expression of fructose bisphosphate aldolase in treated cotton leaves was significantly enhanced on the $10^{\text {th }}$ day of the treatment (3 spots in Figure 2). The identified peptide fragments almost identical to enzyme isoforms available in the Phytozome genome/proteome database except for few amino acid residues out of 397: Gohir.A13G030500.1, Gohir.A13G030400.1, Gohir.D13G028400.1, Gohir.D13G028500.1.

Earlier, expression of these fructose bisphosphate aldolase isoforms identical to Gohir.A13G030500.1 and Gohir.D13G028500.1 was established as having been obtained in the crystal (with the accession num-
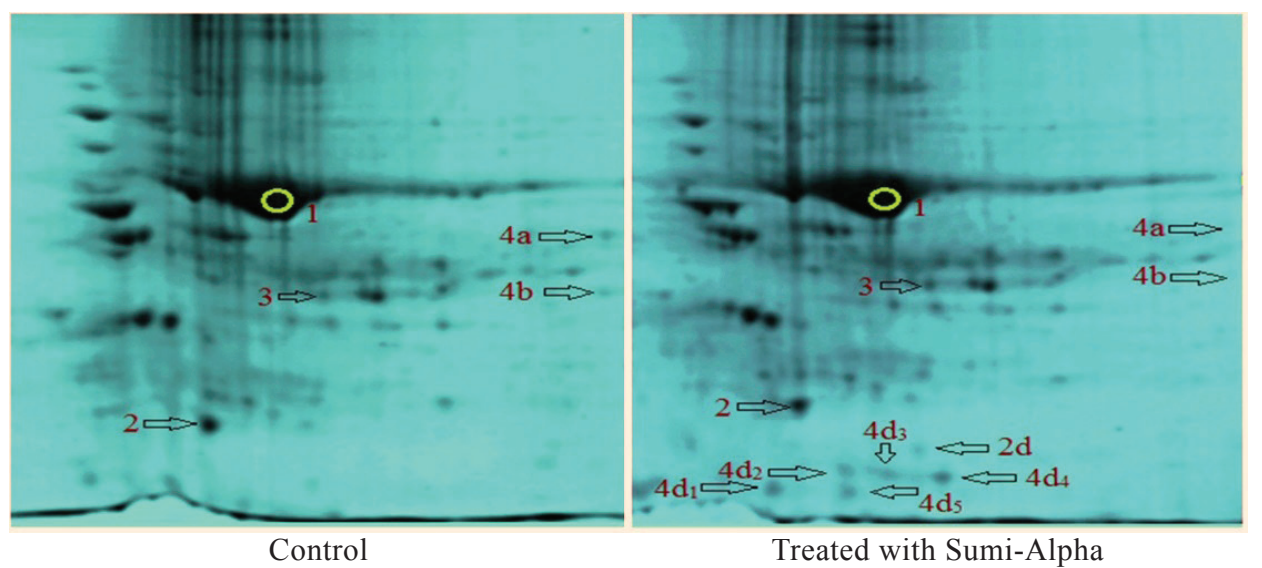

Figure 2. Representative gels with the profiles of soluble proteins from cotton leaves, treated with water (control - A) and Sumi-Alpha (B) (the $10^{\text {th }}$ day of the treatment). Protein spots with remarkable differences between the two conditions were subjected to MS/MS analysis. 
$\mathrm{Tab}$ le 1

Identified MS/MS fragments of RuBisCo in cotton leaves and their correspondence to protein sequences in NCBI database

\begin{tabular}{l}
\hline RuBisCo large subunit (1 spot in Fig.1) / NCBI Reference Sequence: YP_538943.1 \\
\hline MSPQTETKASVGFKAGVKEYKLTYYTPEYEVKDTDILAAFRVTPQPGVPPEEAGAAVAAESSTGTWTT \\
VWTDGLTSLDRYKGRCYDIEPVPGEEDQYICYVAYPLDLFEEGSVTNMFTSIVGNVFGFKALRALRLE \\
DLRVPTAYIKTFQGPPHGIQVERDKLNKYGRPLLGCTIKPKLGLSAKNYGRAVYECLRGGLDFTKDDE \\
NVNSQPFMRWRDRFLFCAEAIFKSQAETGEIKGHYLNATAGTCEEMIKRAMCARELGVPIVMHDYLT \\
GGFTANTSLAHYCRDNGLLLHIHRAMHAVIDRQKNHGMHFRVLAKALRMSGGDHIHAGTVVGKLE \\
GERDITLGFVDLLRDDFIEKDRSRGIYFTQDWVSMPGVLPVASGGIHVWHMPALTEIFGDDSVLQFGG \\
GTLGHPWGNAPGAVANRVALEACVQARNEGRDLAREGNEIIREASKWSPELAAACEVWKAIKFEFDA \\
VDKLDKVEK \\
\hline RuBisCo large subunit partial sequence (2 spot in Fig.1) / GenBank: ADF87884.1 (NCBI) \\
\hline TYYTPEYEVKDTDILAAFRVTPQPGVPPEEAGAAVAAESSTGTWTTVWTDGLTSLDRYKGRCYDIEPV \\
PGEEDQYICYVAYPLDLFEESVTNMFTSIVGNVFGFKALRALRLEDLRVPTAYIKTFQGPPHGIQVER \\
DKLNKYGRPLLGTIKPKLGLSAKNYGRAVYECLRGGLDFTKDDENVNSQPFMRWRDRFLFCAE \\
\hline RuBisCo large subunit partial sequence (2d SPOt in Fig.1)/ GenBank: ADF87884.1 (NCBI) \\
\hline TYYTPEYEVKDTDILAAFRVTPQPGVPPEEAGAAVAAESSTGTWTTVWTDGLTSLDRYKGRCYDIEPV \\
PGEEDQYICYVAYPLDLFEEGSVTNMFTSIVGNVFGFKALRALRLEDLRVPTAYIKTFQGPPHGIQVER \\
DKLNKYGRPLLGCTIKPKLGLSAKNYGRAVYECLRGGLDFTKDDENVNSQPFMRWRDRFLFCAE
\end{tabular}

*N- and C-ends of the identified fragments are shown in bold, RuBisCo large subunit region fitting RuBisCo large subunit partial sequence is underlined, identified MS/MS fragments are shown in dark grey background

bers of A0A1U8K527 and A0A1U8KR66 in UniProt database). The cytosol fructose bisphosphate aldolase is a key enzyme in the glycolytic pathways and can govern the accumulation of water-soluble carbohydrates and synthesis of ATP (Konishi et al. 2004). Promotion of $\mathrm{CO}_{2}$ fixation has been demonstrated in fructose bisphosphate aldolase overexpressed tobacco plants, however, this effect was not linked with RuBisCo activity but with stimulated fructose 1,6-bisphosphate regeneration, which in turn promotes $\mathrm{CO}_{2}$ fixation (Uematsu et al. 2012). Nevertheless, increased accumulation of fructose bisphosphate aldolase in cotton plants leading to increased levels of reducing sugars might represent a food niche- and explain attractiveness to sucking pests (Slosser et al. 2004), which can be linked with an elevated level of reducing sugars and other metabolites in cotton plants, treated with Sumi-Alpha (Asrorov 2013). On the other hand, a compensation function of elevated fructose bisphosphate aldolase as a key metabolic enzyme in energetic processes should be considered as well.

Decreased levels of two proteins - $4 \mathrm{a}$ and $4 \mathrm{~b}$ were found resulted in the formation of five small molecular peptides $-4 d_{1}, 4 d_{2}, 4 d_{3}, 4 d_{4}$, and $4 d_{5}$ in treated samples (Figure 2), and suggested as (possibly negative) interference of Sumi-Alpha with plant processes. The identified sequence, KVAKGKSPRK, in these protein spots, was earlier found in model plant Arabidopsis, in a protein belonging to P-loop containing nucleoside triphosphate hydrolases superfamily (Theologis et al. 2000). The enzyme probably involved in DNA repair and cell cycle. NCBI database reveals that nucleoside triphosphate hydrolase (Gene ID 823899) was found to attenuate oxidative stress and reactive oxygen species. However, conclusions on the link between agrochemical treatment and the accumulation of such protein would be speculative only.

These obtained results indicate the changes in the profile of soluble proteins of cotton leaves after treatment with a pyrethroid insecticide, Sumi-Alpha, and serve as the basis for deeper analysis at a molecular level.

The agrochemical Sumi-Alpha is widely used in Uzbekistan as efficient means against Helicoverpa armigera. However, the subsequent vulnerability of treated plants to sucking insects appears as an undesirable side effect. Our research showed the degradation of $\mathrm{RuBisCo}$ large subunit and/or its partial 
sequence after treatment with Sumi-Alpha. Slight but significant elevation of photosynthetic yield and also fructose bisphosphate aldolase might be linked with the elevated quantity of sugars established in our previous works. We conclude that these mechanisms, in turn, can lead to the accumulation of simple sugars, observed previously, rendering the cotton plants more attractive to sucking pests. Further research is needed to clarify the detailed impact of Sumi-Alpha on cotton fitness as well as defense potential.

Acknowledgments. The work was supported by CASIA (Central Asia Student International Academic exchange with EU, CASIA II, cohort III) project of the European Union Erasmus Mundus Programme.

Ildikó Matušíková contributed in frames of the project financed by the Slovak Research and Development Agency under contract number APVV-150051.

\section{REFERENCES}

AMAD, M. - IQBAL ARIF, M. - DENHOLM, I. 2003. High Resistance of Field Populations of the Cotton Aphid Aphis gossypii Glover (Homoptera: Aphididae) to Pyrethroid Insecticides in Pakistan. In Journal of Economic Entomology, vol. 96, pp. 875-878. https://doi.org/10.1603/0022-049396.3.875.

ANDERSSON, I. - BACKLUND, A. 2008. Structure and function of RuBisCo. In Plant Physiology and Biochemistry, vol. 46, pp. 275-291. https://dx.doi.org/10.1016/j.plaphy.2008.01.001.

ASROROV, A. - MATUŠIKOVA, I. - DALIMOVA, S. - GALOVA, Z. - SULTANOVA, E. - VESHKUROVA, O. - SALIKHOV, Sh. 2016. Agrochemicals affect the antioxidative defense potential of cotton plants. In Journal of Microbiology Biotechnology and Food Sciences, vol. 5, pp. 505-508. http://dx.doi:10.15414/jmbfs.2016.5.6.505-508.

ASROROV, A. - MATUSIKOVA, I. - ISHIMOV, U. - ZIYAVITDINOV, Z. - VESHKUROVA, O. - SALIKHOV, Sh. 2015. Comparative analysis of free amino acids and nitrogen in cotton leaves treated with different classes' insecticides. In Agricultural Research, vol. 4, pp. 277-282. https://doi.org/10.1007/s40003-015-0172-8.

ASROROV, A. - SULTANOVA, E. - VESHKUROVA, O. UZBEKOV, V. - SATTAROV, N. - KHODJAYEV, Sh. SALIKHOV, Sh. 2013. Effects of different classes' insecticides on secondary metabolites of cotton leaves. In The Asian \& Australasian Journal of Plant Science and Biotechnology, Special Issue, pp. 43-47.

CARNEIRO, E. - SILVA, L.B. - MAGGIONI, K. - dos SANTOS, V.B. - RODRIGUES, T.F. - REIS, S.S. - PAVAN, B.E. 2014. Evaluation of insecticides targeting control of Helicoverpa armigera (Hubner) (Lepidoptera: Noctuidae).
In American Journal of Plant Sciences, vol. 5, pp. $2823-$ 2828. http://dx.doi.org/10.4236/ajps.2014.518298.

El-DALY, F.A. 2006. Role of Fenvalerate (Pyrethroid) and Cyanox (Organophosphorus) insecticides on growth and some metabolic activities during seedling growth of Raphanus sativus L. In Pakistan Journal Biological Sciences, vol. 9, pp. 2313-2317. https://doi.org/10.3923/pjbs.2006.2313.2317.

GAO, Z.K. - ZHAO, T. - WANG, M. - ZHANG, W.L. - HE, J.P. - GAO, R.F. 2010. Effects of pesticide on the chlorophyll fluorescence parameters in no-heading Chinese Cabbage. In Acta Horticulturae, vol. 856, pp. 211-216. http:// doi:10.17660/ActaHortic.2010.856.28.

JUNEAU, P. - QIU, B. - DEBLOIS, C.P. 2007. Use of chlorophyll fluorescence as a tool for determination of herbicide toxic effect: Review. In Toxicological \& Environmental Chemistry, vol. 89, pp. 609-625. https://doi. org/10.1080/02772240701561569.

KONISHI, H. - YAMANE, H. - MAESHIMA, M. - KOMATSU, S. 2004. Characterization of fructose-bisphosphate aldolase regulated by gibberellin in roots of rice seedling. In Plant Molecular Biology, vol. 56, pp. 839-848. https://doi. org/10.1007/s11103-004-5920-2.

OERKE, E.C. - DEHNE, H.W. 2004. Safeguarding production-losses in major crops and the role of crop protection. In Crop Protection, vol. 23, pp. 275-285. https://doi. org/10.1016/j.cropro.2003.10.001.

RAVINDHRAN, R. - XAVIER, A. 1997. Effect of pyrethroids on resurgence of aphids (Aphis gossypii G.) and alteration of plant metabolism in cotton. In Pesticide Research Journal, vol. 9, pp. 79-85.

ROY, S. - TYAGI, A. - SHUKLA, V. - KUMAR, A. - SINGH, U.M. et al. 2010. Universal plant DNA barcode loci may not work in complex groups: A case study with Indian Berberis species. In PLoS ONE, vol. 5, no. 10, e13674. https:// dx.doi:10.1371/journal.pone.0013674.

RÓZSAVÖLGYI, T. - HORVÁTH, F. 2008. Effect of pyrethroid insecticides on the photosynthetic activity of pea mesophyll protoplasts. In Acta Biologica Szegediensis, vol. 52, pp. 233-235. http://abs.bibl.u-szeged.hu/index.php/ abs/article/view/2631.

SLOSSER, J.E. - PARAJULEE, M.N. - HENDRIX, D.L. HENNEBERRY, T.J. - PINCHAK, W.E. 2004. Cotton Aphid (Homoptera: Aphididae) abundance in relation to cotton leaf sugars. In Environmental Entomology, vol. 33, pp. 690-699. https://doi.org/10.1603/0046-225X-33.3.690.

TÉTARD-JONES, C. - GATEHOUSE, A.M.R. - COOPER, J. - LEIFERT, C. - RUSHTON, S. 2014. Modelling pathways to RuBisCo degradation: A structural equation network modelling approach. In PLOS ONE, vol. 9, no. 2, e87597. https://dx.doi.org/10.1371/journal.pone.0087597.

THEOLOGIS, A. - ECKER, J.R. - PALM, C.J. - FEDERSPIEL, N.A. - KAUL, S. - WHITE, O. - ALONSO, J. et al. 2000. Sequence and analysis of chromosome 1 of the plant Arabidopsis thaliana. In Nature, vol. 408, pp. 816-820. https://doi.org/10.1038/35048500.

UEMATSU, K. - SUZUKI, N. - IWAMAE, T. - INUI, M. YUKAWA, H. 2012. Increased fructose 1,6-bisphosphate aldolase in plastids enhances growth and photosynthesis of tobacco plants. In Journal of Experimental Botany, vol. 63, pp. 3001-3009. http://dx.doi.org/www.doi:10.1093/jxb/ ers004.

ZAHID, M. - HAMED, M. 2003. Comparative efficacy of insecticides against the American "Hub." of Cotton. In Journal of Science Education and Technology, vol. 25, pp. 169 -173 .

Received: November 11, 2019 Accepted: March 23, 2020 